\title{
Chemical compounds contained in young and mature leaves of agarwood species Wikstroemia tenuiramis and its antioxidant properties
}

\author{
RIDWANTI BATUBARA ${ }^{1, \bullet}$, TENGKU ISMANELLY HANUM ${ }^{2}$, ODING AFFANDI $^{1}$, HENNY SRI WAHYUNI ${ }^{2}$ \\ ${ }^{1}$ Program of Forestry, Faculty of Forestry, Universitas Sumatera Utara. Jl. Tridharma Ujung No. 1, Padang Bulan, Medan 20155, North Sumatra, \\ Indonesia. Tel.: +62-61-8220605, Fax.: +62-61-8201920. •email: ridwantibb@yahoo.com, ridwanti@usu.ac.id \\ ${ }^{2}$ Faculty of Pharmacy, Universitas Sumatera Utara. Jl. Tridharma Ujung No. 4, Padang Bulan, Medan 20155, North Sumatra, Indonesia
}

Manuscript received: 4 August 2020. Revision accepted: 13 September 2020.

\begin{abstract}
Batubara R, Hanum TI, Affandi O, Wahyuni HS. 2020. Chemical compounds contained in young and mature leaves of agarwood species Wikstroemia tenuiramis and its antioxidant properties. Biodiversitas 21: 4616-4622. The genus Wikstroemia is one of the genus of agarwood producing trees which has not been widely researched and published. One type of this genus is Wikstroemia tenuiramis Miq, which grows naturally in North Sumatra, the leaves are like other types of agarwood leaves can be used as raw material for agarwood leaves tea. A research has been conducted to determine the chemical contents contained in the young and mature leaves of agarwood plants species $W$. Tenuiramis. This research methods applied qualitative analysis using phytochemical screening, quantitative analysis to determine tannin content using titration method, antioxidant activity analysis using 2,2-diphenil-1-picrylhydrazil (DPPH) method, and compound tracing using Py-gas chromatography-mass spectrometry (Py-GC-MS) instruments. The qualitative phytochemical analysis results showed no difference in chemical compounds contained in both the young and mature leaves. Both the young and mature leaves contained flavonoids, triterpenoids, and tannins, and did not contain alkaloids, steroids and saponins. The young contained tannins of $1.079 \pm 0.001 \%$ and the mature contained tannins of $4.645 \pm 0.021 \%$, not significant statistically. Py-GC-MS analysis showed the presence of various 30 bioactive compounds contained in both young and mature leaves. The analysis results also showed that both the young and mature leaves had very strong antioxidant activity. Our findings suggest that the two types of leaves have equal utility value of in term of chemical contents and antioxidant potentials.
\end{abstract}

Keywords: Agarwood, antioxidants, mature leaves, phytochemicals, py-GC-MS, young leaves, Wikstroemia tenuiramis

\section{INTRODUCTION}

Agarwood-producing plant is one of the important plants of forest in Indonesia. The aromatic end products of agarwood have been used in several countries, such as India, Singapore, Malaysia, Japan, the Middle East and the United States. The geographical distribution of agarwood species is widespread in Java, Sumatra, Kalimantan, Sulawesi, Maluku, Nusa Tenggara, and Papua, and it can almost be found in various forest habitats and conditions (Sumarna 2002). Taxonomically, agarwood-producing plants belong to the Sub-Class of Archichlamydeae. The plants consist of three families, namely Thymeleaceae, Euphorbiaceae and Leguminoceae with eight genera, namely Aquilaria, Aetoxylon, Dalbergia, Enkleia, Excoecaria, Gonystylus, Gyrinops and Wiststroemia. In Indonesia, there are currently 27 species of agarwood known to have a living form of trees, shrubs, bushes, and/or as vines (Sumarna 2012).

More recently, research and use of agarwood leaf as an antioxidant by serving it as a contemporary herbal tea beverage product have been developed, revealing the pharmacological properties of agarwood tea derived from the leaves of Aquilaria (Thymelaeaceae) (Adam et al. 2017). This potential research theme is beneficial to be expanded to other genera and species, and not only on the well-known Aquilaria genus. Phytochemical screening on water extract of agarwood leaves showed contents of phenolic compounds, flavonoids, and steroids (Parwata et al. 2016). The leaves of Grynops versteegii contained secondary metabolites of flavonoids, terpenoids and phenolic compounds (Mega and Swastini 2010). Aquilaria spp. as a source of compounds beneficial to health has been reviewed regarding the traditional uses, phytochemicals, and pharmacological properties (Hashim et al. 2016). In Thailand, the leaves of Aquilaria crassna have been used traditionally for the treatments of various disorders (Sattayasai et al. 2012).

Another genus of agarwood producing plants is Wikstroemia. Each species of agarwood has a specific area of distribution and ecology (Mulyaningsih and Yamada 2008). Wikstroemia androsaemifolia Decne. was found in Sumba. Another species is Wikstroemia tenuiramis Miq or in the local languages known as known as "gaharu cengkeh". The distribution of $W$. tenuiramis is Sumatra, Bangka and Kalimantan (Sumarna 2012).

The species of agarwood W. tenuiramis is a species of agarwood-producing plants that has not been widely studied, especially in the utilization of parts of the tree, specifically its leaves. However, the phytochemical contents varied, depending on the location of leaf sampling (Asmaliyah et al. 2016), and were also influenced by growth factors or maturity of the leaves. For example, the mature leaves of Clausena lansium have the same utility values as leaf buds and could be used as sustainable and economical sources of bioactive compounds for 
nutraceutical and pharmaceutical industrial applications (Chang et al. 2018). The leaf age influence their antioxidants and phytochemicals (phenols and flavonoids) properties (Anwar et al. 2017). Therefore, this research aimed to investigate the chemical contents of young and mature leaves of $W$. tenuiramis and its antioxidant potential. We expect the results of the study provide a new knowledge on whether there is difference between young and mature leaves of $W$. tenuiramis in term of chemical contents and antioxidant potential to inform the utility value of the two types of leaves.

\section{MATERIALS AND METHODS}

\section{Time and location research}

This research was conducted in October 2017-March 2018. Sample materials were collected from Siantona village, Mandailing Natal District, North Sumatra Province, Indonesia. Raw material preparation, determination of moisture content, and ethanol extraction were carried out at the Forest Product Technology Laboratory, Faculty of Forestry, Universitas Sumatera Utara (USU), Medan, Indonesia. Tannin content was analyzed at the Food Technology Laboratory, Faculty of Agriculture, Universitas Sumatera Utara. Phytochemical screening was carried out at the Laboratory of Biological Natural Chemistry, Faculty of Mathematics and Natural Sciences, USU. Meanwhile, the Py-GC-MS analysis was conducted at the Forest Research and Development Center, Bogor.

\section{Research procedure}

Sampling and plant identification

The samples used in this research were the leaves of $W$. tenuiramis. The samples of young and mature leaves were collected and sorted by leaves color (Figure 1).

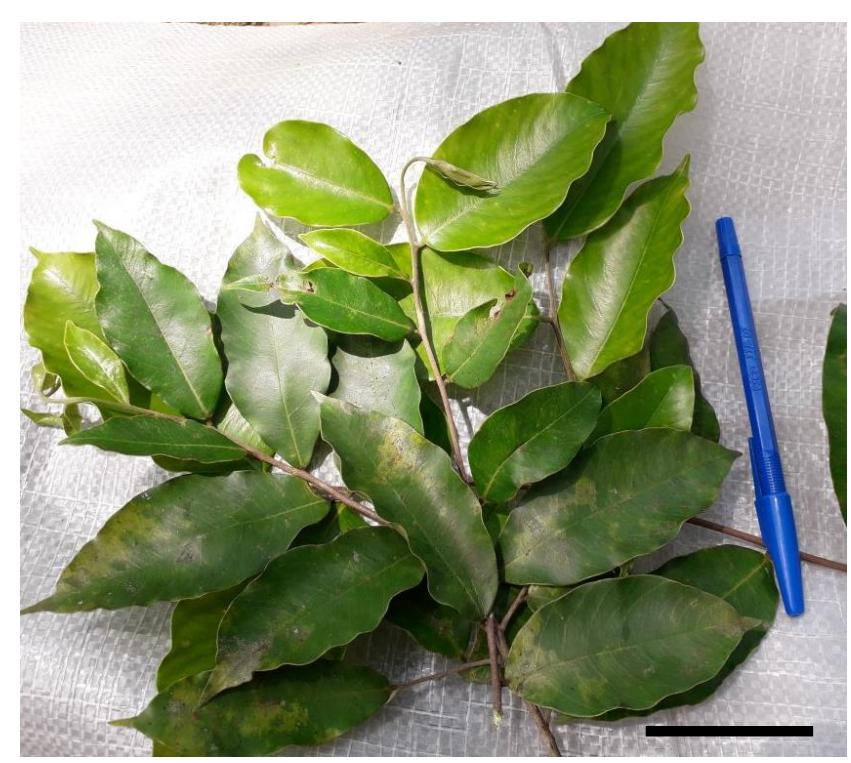

Figure 1. The leaves of Wikstroemia tenuiramis Miq. Bar $=5 \mathrm{~cm}$.

\section{Raw material preparation}

The agarwood leaf samples were rinsed with flowing water then spread on parchment paper until the water was absorbed. Then, the samples were dried in a drying cabinet with temperature of $400-500^{\circ} \mathrm{C}$ until dry and brittle. The drying aimed to get the simplicia not easily rotten, therefore, can be stored for a longer period. Dried leaves were blended into powder using a blender then put into a sun-protected container before extraction and analysis.

\section{Ethanol extraction of agarwood leaves}

The extraction procedure used maceration method following the guidance by Ditjen POM (1995) using ethanol $96 \%$ as solvent. As much as $200 \mathrm{~g}$ of simplicia powder of $W$. tenuiramis leaves, both the young and the mature, were put into a glass container, poured with 1500 $\mathrm{mL}$ of ethanol $96 \%$, kept always closed and protected from light, and occasionally stirred. After five days, the mixture was filtered. The residue then was soaked with ethanol $96 \%$ sufficiently to obtain $2000 \mathrm{ml}$ of mixture, then transferred into a closed vessel and left in a cool place protected from light for two days, then filtered. The filtrate was concentrated using a rotary evaporator at $40{ }^{\circ} \mathrm{C}$ until a thick liquid was obtained and then dried using a freeze dryer to become a dry extract.

\section{Characterization, determination of moisture content and tannin content analysis}

Characterization was carried out on ethanol extracts of the young and mature leaves with organoleptic specific parameters of color, taste and aroma. Moisture content was determined using gravimetric method. Meanwhile, tannin content was analyzed using titration method with $\mathrm{KMnO}_{4}$ solution.

\section{Phytochemical screening}

Phytochemical screening was carried out using the Farnsworth method (1996) on the ethanol extracts. The screening covered examinations of bioactive compounds contained in young and mature leaves of W. tenuiramis agarwood including groups of organic compounds such as alkaloids, glycosides, flavonoids, steroids/terpenoids, tannins and saponins.

\section{DPPH scavenging activity assay}

The ability of the sample to trap DPPH (1,1-diphenil-2picrylhydrazil) as a free radical in methanol solution with an $\mathrm{IC}_{50}$ value was used as a parameter to determine the antioxidant activity of the test sample (Prakash 2001). The power of plant extracts to scavenge DPPH free radicals was specified following the methods by Prakash (2001) and Molyneux (2004). The measured absorbance was made at $517 \mathrm{~nm}$, with positive control (ascorbic acid). The percentages of inhibition of the DPPH free radical, as a function of the impact extracts concentrations, were calculated using the equation:

$$
\% \text { Inhibition }=\frac{A_{\text {control }}-A_{\text {Test }}}{A_{\text {control }}} \text {, }
$$

Where: $A_{\text {control }}=$ absorbance of control; $A_{\text {Test }}=$ absorbance of samples. 
The IC50 values indicate the concentration of samples that is needed to trap 50\% of DPPH free radical. The IC50 was estimated by nonlinear regression using Excel version 2013.

\section{Py-GC-MS analysis}

To identify the bioactive compounds in young and mature leaves of agarwood, the GC-MS analysis was performed using the Py-GC-MS instrument. Pyrolysis-Gas Chromatography/Mass Spectrometry (Py-GC/MS) is an instrumental method that enables a reproducible characterization of intractable and non-volatile macromolecular compounds. It entails application of thermal energy in a helium atmosphere to produce volatile fragments and products from a macromolecule compounds capable of being analyzed using GC/MS. It differs from GC/MS in the type of sample analysed and the method by which it is introduced to the GC/MS system. Instead of the direct injection of a highly refined organic solution, a few $\mu \mathrm{g}$ of the original natural material is nalysed directly. Thus compounds that are not amenable to analysis by GC and GC/MS are ideal candidates for Py-GC/MS analysis (Sithole et al. 2013). Py-GC/MS is a technique that uses a microscale pyrolysis unit to pyrolyze organic material on a micro-to milligram scale (Ware 2013). PyGC/MS is an important technique for biomass characterization, because it involves not only the compositional information of the complex component macromolecules, but also the characteristics of volatile pyrolysis products (Gao et al. 2013). The type of tool used is the Shimadzu GCMS-QP 2010.

\section{RESULTS AND DISCUSSION}

\section{Extract characterization, phytochemical screening results, and tannin content}

Dry concentrated extracts obtained had moisture content of less than $10 \%$. There was no difference between the extract of young and mature leaves (Table 1). Similarly, for the characteristics regarding organoleptic evaluation, there was no difference as well. The difference was only at the yield. The mature leaves yielded more extract than the young ones. However, people commonly consume agarwood leaves regardless of the leaves maturity while mature leaves yield the optimum ability to produce secondary metabolites and therefore the levels of phenolic and flavonoid contents were high (Anwar et al. 2017).

Phytochemical screening was carried out on agarwood leaf extracts to obtain information on secondary metabolite compounds contained in both young leaves and old leaves of $W$. tenuiramis. Table 2 showed the results of the phytochemical screening. Phytochemical screening on the young and mature leaves showed no differences in the groups of chemical compounds.

The quality of tea is affected by the maturity of the leaves and the processing method applied to them. Leaves maturity affects the content and type of polyphenols. Flavonoids and tannins are included in group of polyphenol compounds. Phytochemical screening result obtained provides important information about the chemical compounds contained in the leaves of $W$. tenuiramis agarwood qualitatively. Meanwhile, quantitatively, the mature leaves yielded higher than the young ones. Because the phytochemical results showed that both of them positively contained tannin compounds, further quantitative analysis were carried out on tannins.

Table 1. Characterization results of Wikstroemia tenuiramis leaves ethanol extract

\begin{tabular}{lll}
\hline \multirow{2}{*}{ Parameters } & \multicolumn{2}{c}{ Leaves ethanol extract } \\
\cline { 2 - 3 } & \multicolumn{1}{c}{ Young } & \multicolumn{1}{c}{ Mature } \\
\hline Yield (\%) & $7.40 \pm 0.28$ & $8.30 \pm 0.14$ \\
Moisture content (\%) & $5.35 \pm 0.01$ & $5.13 \pm 0.06$ \\
Organoleptic properties: & & \\
Color & Greenish brown & Greenish brown \\
Taste & Chelate & Chelate \\
Smell & Weak aromatic & Weak aromatic \\
\hline
\end{tabular}

Table 2. Phytochemical screening results of Wikstroemia tenuiramis. leaves ethanol extract

\begin{tabular}{lcc}
\hline \multirow{2}{*}{ Compounds } & \multicolumn{2}{c}{ Leaves ethanol extract } \\
\cline { 2 - 3 } & Young & Mature \\
\hline Alkaloids & - & - \\
Flavonoids & + & + \\
Tannin & + & + \\
Saponin & - & - \\
Triterpenoid & + & + \\
\hline Note: & containing
\end{tabular}

Note: +: containing the compound, -: not containing the compound

Table 3. Tannins content of Wikstroemia tenuiramis leaves ethanol extract

\begin{tabular}{lc}
\hline Type of the leaves & Tanin content $(\%)$ \\
\hline Young & $1.079 \pm 0.001$ \\
Mature & $4.645 \pm 0.021$ \\
\hline
\end{tabular}

The tannin compounds contained in the mature leaves of agarwood species W. tenuiramis are higher than those in the young leaves (Table 3). These results are in accordance with those from previous study on other plants. For example, the level of phenolic and flavonoids compound contained in mature leaves of Aquilaria beccariana was higher than in the young and the older leaves (Anwar et al. 2017). Tea drink made from young leaves of seagrass (Enhalus acoroides) has lower flavonoids level of $0.0888 \%$, or in other words, tea drink made from the old leaves has higher level of flavonoids total average value compared to young leaves (Tehubijuluw et al. 2018). Additionally, the level of maturity of the leaves, in general, affects the content and the type of polyphenols contained in the leaves of gambier plants (Pambayun et al. 2007). 
In contrast, polyphenols contained in young leaves of tea (Camellia sinensis) are higher than the mature ones (Izzreen and Fadzelly 2013). Hasan et al. (2000) noted that the younger the tea leaf, the higher the total phenol and catechin. The polyphenols level contained in the young leaf tea is higher than in the old leaf because the aging led to significantly reduced moisture and total phenolic content, therefore, the phenolic profiles also significantly change as the tea leaf getting mature (Liu et al. 2020).

\section{GC-MS Analysis}

The results of Py GC-MS analysis are displayed in the form of chromatograms for the highest Retention Time and Concentration (Figures 2 and 3) and the list of compounds identified as constituents contained in the extract of young and mature leaves of agarwood species W. tenuiramis (Table 4 and 5). Both the young and mature leaves contained 30 compounds, but the type of the compounds varied. Among the 30 compounds identified, there were only 13 similar compounds contained in the extract of both the young and mature leaves.

The constituents contained in the young leaves of $W$. tenuiramis (Table 4) consisted 11 compounds with concentrations of more than $3 \%$, and among them the top three main constituents were Octadecanoic acid (CAS) Stearic acid (17.42\% ); Cyclopropane, 1,1-dibromo-2chloro-2-fluoro-(CAS) 1,1-DIBROMO-2-CHLO (10.75\%); 9,12-Octadecadienal (CAS) $(8.98 \%)$. The most constituent compounds were acidic compounds.

Meanwhile, the main constituents in the mature leaves (Table 5) consisted of 10 compounds with three main compounds were Octadecanoic acid (CAS) Stearic acid (17.44\%); Heptanoic acid (CAS) Heptoic acid (11.40\%); 1,4-diaza-2,5-dioxo-3-isobutyl bicyclo [4.3.0] nonane $(10.57 \%)$. As well as in the young leaves, the main constituents of the mature leaves were also dominated by acidic compounds.

For comparison, the main content of chemical compounds contained in the methanol extract of Pangi (Pangium edule Reinw) leaves is octadecadienic acid $24.60 \%$, whereas the leaves are classified in noncommercial herbs and only used as vegetables by the local community (Tony et al. 2017). Hence, the chemical compounds contained in the leaves of $W$. tenuiramis need to be studied in terms of their potential and subsequent uses.

The leaf of $W$. tenuiramis contained Heptanoic acid (CAS) Heptoic acid (Table 4 and 5). Heptanoic acid is used in the preparation of esters, such as ethyl heptanoate, which are used in fragrances and as artificial flavors. Heptanoic acid is used to esterify steroids in the preparation of drugs such as testosterone enanthate, trenbolone enanthate, drostanolone enanthate, and methenolone enanthate (Primobolan). The triglyceride ester of heptanoic acid is the triheptanoin, which is used in certain medical conditions as a nutritional supplement (Annaken et al. 2006).

\section{Antioxidant potentials of the leaves of Wikstroemia tenuiramis}

In this research, the mature leaves extract of $W$. tenuiramis had stronger antioxidant activity (IC50 value of
$25.860 \pm 0.721 \mathrm{ppm}$ ) than the young leaves (IC50 value of $26.585 \pm 0.689 \mathrm{ppm})$. However, both are in the same interval category which is very strong (IC50 values $<50$ $\mathrm{ppm}$ ), and not significant statisticcally, therefore, has great potential as sources of antioxidants. Indeed, having strong capacity to act as powerful antioxidants are due to the content of phenolic and flavonoids compounds contained in both the young and the mature leaves are shown in the Tables 2 and 3, where the level of phenolic compounds (i.e. tannins) contained in the mature leaves is higher than in the young. Therefore, it can be infered that the phenolic and flavonoid compounds contained in the $W$. tenuiramis leaves contribute to the antioxidant activity. For comparison, the mature leaves of agarwood species A. beccariana that were suggested as the potential antioxidant had IC50 value of 72.25+0.72 ppm (Anwar et al. 2017).

Leaf's extract of the naturally grown $W$. tenuiramis from Mandailing Natal District, Indonesia had IC50 value of 30.482 (Batubara et al. 2019). This is comparable to the IC50 value of $A$. mallacensis Lamk cultivated in the same district with $41.130 \mu \mathrm{g} / \mathrm{ml}$ (Batubara et al. 2019). These suggest that the extract of the leaf of $W$. tenuiramis has the potential to developed into alternative tea beverage which is rich in antioxidants. Moreover, chemical content analysis on the two agarwood species mentioned above showed that the leaves positively contained alkaloids, flavonoids, steroids/triterpenoids, and tannins (Batubaral et al. 2018). Antioxidant activity of ethanol extract and water extract of $W$. tenuiramis is very strong with IC50 values of 27.78 and $28.80 \mu \mathrm{g} / \mathrm{ml}$ in the fresh leaves in ethanol solvent and hot water, respectively, and IC50 values of 25,35 and 28,59 $\mu \mathrm{g} / \mathrm{ml}$ for the rotten leaves in ethanol solvent and hot water, respectively (Surjanto et al. 2019).

The results of Py GC-MS analysis also support the antioxidant analysis results since the major compounds contained in both the young and the mature leaves were identified as acid compounds, namely Octadecanoic acid (CAS) Stearic acid. Batubara et al. (2020) noted that the primary compound with the highest concentration in agarwood (A. malaccensis) leaves from Laru Village is also Octadecanoic acid (CAS) Stearic acid, contributing to the great role in strong antioxidant capacity of agarwood leaves.

Contrary to the $W$. tenuiramis leaves, the young leaves of Vernonia amygdalina possess higher antioxidant and antidiabetic potentials than the old leaves, and differ in their phytochemical compositions and also in pancreatic and hepatic regenerational abilities (Asante et al. 2016). Pomegranate leaves are also an important source of potentially healthy bioactive compounds and antioxidants. Total levels of phenolics and flavonoids decreased significantly in the early stages of leaf growth. However, concentrations of total alkaloids increased during leaf growth and development. Antioxidant activities in pomegranate leaves were significantly correlated with the level of total phenolics and flavonoids. All bioactive compounds measured from pomegranate leaves increased during leaf growth and development (Zhang et al. 2010). 


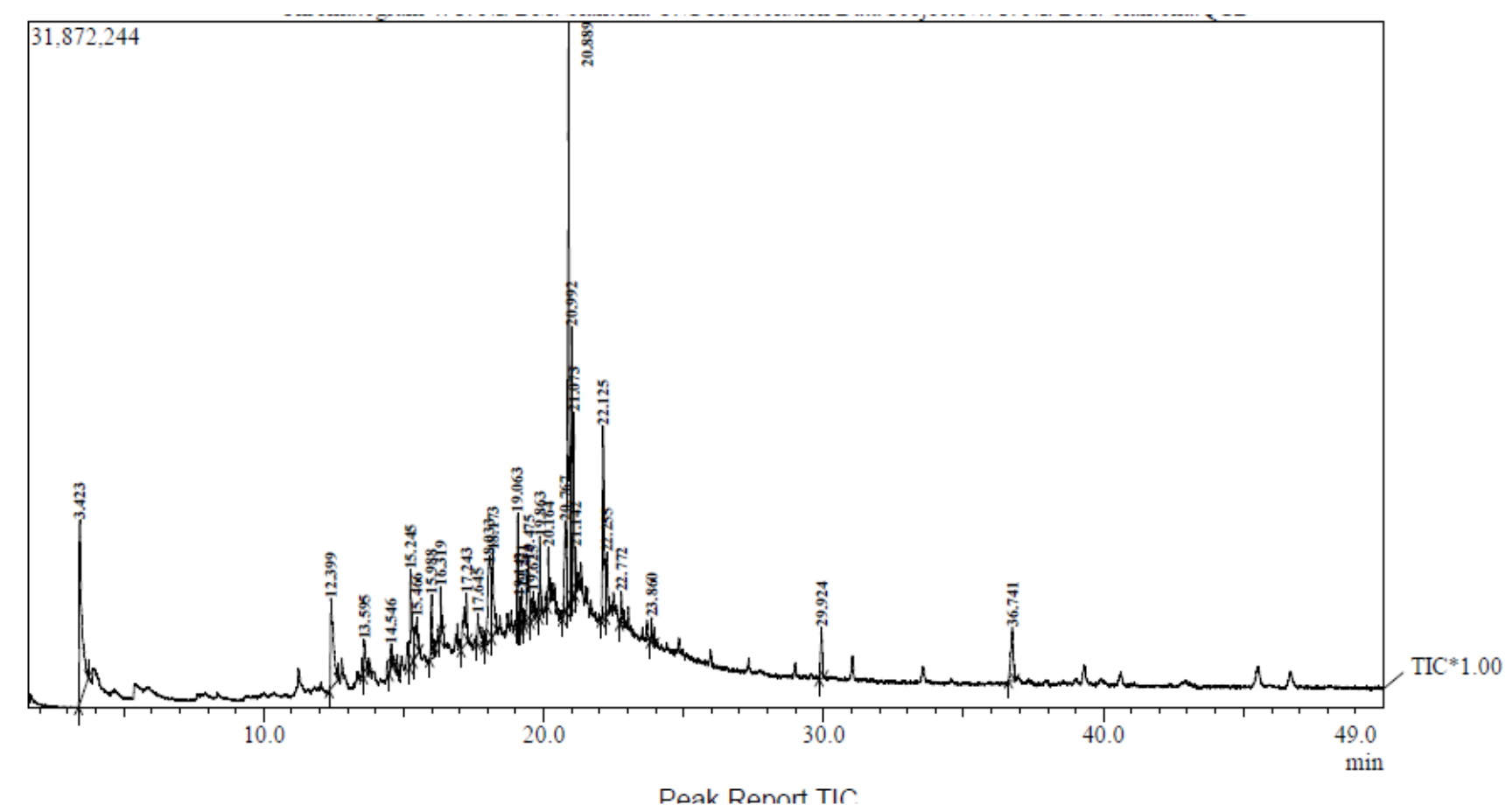

Figure 2. GC-MS chromatogram of ethanol extract from the young leaves of Wikstroemia tenuiramis

Table 4. Chemical constituents of ethanol extract from the young leaves of Wikstroemia tenuiramis as detected by GC-MS

\begin{tabular}{|c|c|c|c|}
\hline Peak & $\begin{array}{c}\text { Retention time } \\
(\mathbf{R t})\end{array}$ & $\begin{array}{c}\text { Concentration } \\
(\%)\end{array}$ & Name of chemical constituent \\
\hline 1 & 3.423 & 10.75 & Cyclopropane, 1,1-dibromo-2-chloro-2-fluoro-(CAS) 1,1-DIBROMO-2-CHLO \\
\hline 2 & 12.399 & 5.65 & Carbamic acid, phenyl ester (CAS) Phenyl carbamate \\
\hline 3 & 13.595 & 1.39 & Phenol, 2-methyl-(CAS) o-Cresol \\
\hline 4 & 14.546 & 0.61 & Heptanoic acid (CAS) Heptoic acid \\
\hline 5 & 15.245 & 3.77 & Benzaldehyde, 4-methyl-(CAS) p-Tolualdehyde \\
\hline 6 & 15.466 & 2.56 & Decanoic acid (CAS) Capric acid \\
\hline 7 & 15.988 & 1.81 & Benzonitrile, 2-methyl-(CAS) 1-Methyl-2-cyanobenzene \\
\hline 8 & 16.319 & 0.86 & Phenol, 2,6-dimethoxy-(CAS) 2,6-Dimethoxyphenol \\
\hline 9 & 17,243 & 2,74 & Tetradecane, 1-chloro-(CAS) Myristyl chloride \\
\hline 10 & 17.645 & 1.95 & Cyclohexane, (3-chloro-1-propynyl)-(CAS) 3-CHLORO-1-CYCLOHEXYLPR \\
\hline 11 & 18.033 & 6.04 & Heptanoic acid (CAS) Heptoic acid \\
\hline 12 & 18.173 & 3.03 & 4-Hydrazinyltoluene \\
\hline 13 & 19.063 & 1.39 & Silane, trichloroeicosyl- \\
\hline 14 & 19.142 & 0.36 & Silane, trichloroeicosyl- \\
\hline 15 & 19.221 & 0.79 & 3,5-Dodecadiyne, 2-methyl-(CAS) 2-METHYLDODEC-3,5-DIYNE \\
\hline 16 & 19.475 & 3.51 & Cyclopentaneundecanoic acid (CAS) 11-CYCLOPENTANYLUNDECANOIC \\
\hline 17 & 19.625 & 1.05 & Benzoyl cyanide \\
\hline 18 & 19.863 & 1.28 & 11-Tetradecen-1-ol, acetate, (Z)-(CAS) cis-11-Tetradecenyl acetate \\
\hline 19 & 20.164 & 1.38 & 11-Tetradecen-1-ol, acetate, (Z)-(CAS) cis-11-Tetradecenyl acetate \\
\hline 20 & 20.767 & 3.44 & 9,12-Octadecadienal (CAS) \\
\hline 21 & 20.889 & 17.42 & Octadecanoic acid (CAS) Stearic acid \\
\hline 22 & 20.992 & 8.98 & 9,12-Octadecadienal (CAS) \\
\hline 23 & 21.073 & 3.54 & 1,4-diaza-2,5-dioxo-3-isobutyl bicyclo[4.3.0]nonane \\
\hline 24 & 21.142 & 0.70 & 1,4-diaza-2,5-dioxo-3-isobutyl bicyclo[4.3.0]nonane \\
\hline 25 & 22.125 & 6.45 & 9-Octadecenoic acid (Z)-(CAS) Oleic acid \\
\hline 26 & 22.255 & 2.55 & Silane, trichloroeicosyl- \\
\hline 27 & 22.772 & 0.93 & 2-Undecanethiol, 2-methyl-(CAS) 2-Methylundecyl-2-thiol \\
\hline 28 & 23.860 & 0.72 & 1-Nonene, 4,6,8-trimethyl-(CAS) 4,6,8-TRIMETHYLNONENE-1 \\
\hline 29 & 29.924 & 1.64 & trans-Farnesol \\
\hline 30 & 36.741 & 2.72 & Tricosane, 2-methyl-(CAS) 2-Methyltricosane \\
\hline
\end{tabular}




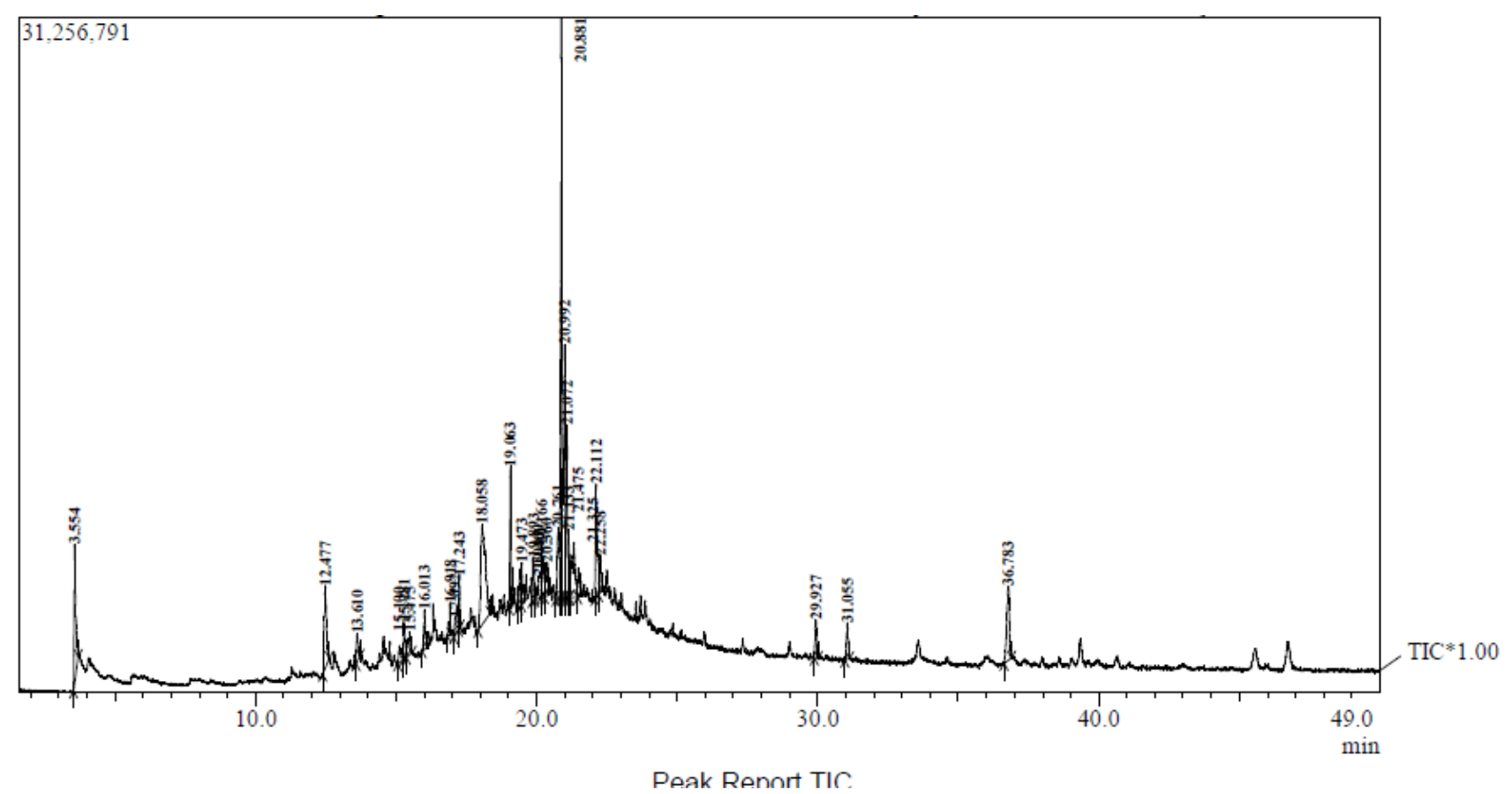

Figure 3. GC-MS chromatogram of ethanol extract from the mature leaves of Wikstroemia tenuiramis

Table 5. Chemical constituents of ethanol extract from the young leaves of Wikstroemia tenuiramis as detected by GC-MS

\begin{tabular}{|c|c|c|c|}
\hline Peak & $\begin{array}{l}\text { Retention time } \\
\text { (Rt) }\end{array}$ & $\begin{array}{c}\text { Concentration } \\
(\%)\end{array}$ & Name of chemical constituent \\
\hline 1 & 3.554 & 5.53 & Nitrogen oxide (N2O) (CAS) Nitrous oxide \\
\hline 2 & 12.477 & 4.45 & Cyclohexene, 1-methyl-4-(1-methylethenyl)-(CAS) 1-P-MENTHA-1,8-DIENE \\
\hline 3 & 13.610 & 1.02 & Phenol, 2-methyl-(CAS) o-Cresol \\
\hline 4 & 15.100 & 1.04 & 2-Propenoic acid, 2-methyl-, ethyl ester (CAS) Ethyl methacrylate \\
\hline 5 & 15.281 & 1.36 & Benzaldehyde, 4-methyl-(CAS) p-Tolualdehyde \\
\hline 6 & 15.475 & 1.45 & Heptanoic acid (CAS) Heptoic acid \\
\hline 7 & 16.013 & 1.51 & 7-CYANO(15N)-CYCLOHEPTATRIENE \\
\hline 8 & 16.918 & 0.85 & Dodecane (CAS) n-Dodecane \\
\hline 9 & 17.092 & 1.51 & 1-Nonyne (CAS) 1-C9H16 \\
\hline 10 & 17.243 & 0.77 & Tetradecane (CAS) n-Tetradecane \\
\hline 11 & 18.058 & 11.40 & Heptanoic acid (CAS) Heptoic acid \\
\hline 12 & 19.063 & 1.99 & 1-Dodecene (CAS) Adacene 12 \\
\hline 13 & 19.400 & 1.37 & 9,12-Octadecadienal (CAS) \\
\hline 14 & 19.473 & 1.22 & Tetradecanoic acid (CAS) Myristic acid \\
\hline 15 & 19.893 & 1.27 & Silane, trichloroeicosyl- \\
\hline 16 & 20.083 & 1.64 & Propanedinitrile, (2-methylcyclohexylidene)-(CAS) \\
\hline 17 & 20.166 & 2.49 & Octadecanal (CAS) Stearaldehyde \\
\hline 18 & 20.36 & 2.26 & 2-Butanone, 4-cyclohexyl-(CAS) 4-Cyclohexyl-2-butanone \\
\hline 19 & 20.761 & 3.06 & 9,15-Octadecadienoic acid, methyl ester (CAS) METHYL 9,15-OCTADECAD \\
\hline 20 & 20.881 & 17.44 & Octadecanoic acid (CAS) Stearic acid \\
\hline 21 & 20.992 & 10.57 & 1,4-diaza-2,5-dioxo-3-isobutyl bicyclo[4.3.0]nonane \\
\hline 22 & 21.072 & 4.46 & 9,12 -Octadecadienal (CAS) \\
\hline 23 & 21.133 & 1.50 & 1,4-diaza-2,5-dioxo-3-isobutyl bicyclo[4.3.0]nonane \\
\hline 24 & 21.325 & 4.87 & 5,10-DIETHOXY-2,3,7,8-TETRAHYDRO-1H,6H-DIPYRROLO[1,2-A;1',2'-D]P \\
\hline 25 & 21.475 & 0.84 & 2,4,6-Trimethyl-1-nonene \\
\hline 26 & 22.112 & 4.43 & 9-Octadecenoic acid (Z)-(CAS) Oleic acid \\
\hline 27 & 22.258 & 2.03 & Silane, trichloroeicosyl- \\
\hline 28 & 29.927 & 1.49 & trans-Farnesol \\
\hline 29 & 31.055 & 1.58 & Heptadecane, 2-methyl-(CAS) 2-Methylheptadecane \\
\hline 30 & 36.783 & 4.58 & Tricosane, 2-methyl-(CAS) 2-Methyltricosane \\
\hline
\end{tabular}


In conclusion, the ethanol extract from both young and mature leaves of agarwood species $W$. tenuiramis contains the same three phytochemical compounds, namely flavonoids, triterpenoids, and tannins. Futhermore, GC-MS analysis was able to detect the presence of 30 various bioactive compounds contained in both leaves including the same 13 compounds with Octadecanoic acid (CAS) Stearic acid as the highest constituent. These chemical contents, therefore, contribute to the strong antioxidant activity of the ethanol extracts from both young and mature leaves with the IC50 value of $26.585 \pm 0.689 \mathrm{ppm}$ and $25.860 \pm 0.721 \mathrm{ppm}$, respectively.

\section{ACKNOWLEDGEMENTS}

The authors would like to acknowledge the Rector of University of Sumatera Utara (USU), Medan, Indonesia for funding support towards this research under the scheme of Penelitian Dasar TALENTA USU 2017.

\section{REFERENCES}

Adam AZ, Lee SY, Mohamed R. 2017. Pharmacological properties of agarwood tea derived from Aquilaria (Thymelaeaceae) leaves: An emerging contemporary herbaldrink. J Herb Med 10: 37-44. DOI 10.1016/j.hermed.2017.06.002

Annaken DJ, Both S, Christoph R, Fieg G, Steinbener U, Westfechtel A. 2006. Fatty Acids in Ullmann's Encyclopedia of Industrial Chemistry. Wiley-VCH, Weinheim. DOI: 10.1002/14356007.a10_245.pub2

Anwar K, Triyasmono L, Rizki MI, Halwani W, Lestari F. 2017. The influence of leaf age on total phenolic, flavonoids, and free radical scavenging capacity of Aquilaria beccariana. Res J Pharm Biol Chem Sci 8 (1S): 129-133.

Asante DB, Effah-Yeboah E, Barnes P, Abban HA, Ameyaw EO, Boampong JN, Ofori EG, Dadzie JB. 2016. Antidiabetic effect of young and old ethanolic leaf extracts of Vernonia amygdalina: A comparative study. J Diabetes Res 2016: 8252741. DOI: $10.1155 / 2016 / 8252741$.

Asmaliyah, Hadi EE, Muslimin I, Turjaman M, Thalib I. 2016 Quantitative pre-eliminary phytochemical screening of aqueous extracts of leaves of Oroxylum indicum from five different places in Sumatra Island, Indonesia. IJPPR 8 (11): 1863-1869.

Batubara R, Hanum TI, Surjanto. 2018. Phytochemical and tannin conten in two species of agarwood leaves from Mandailing Natal Regency North Sumatera Province. AIP Conf Proc 2049: 030009-1-030009-5. DOI: $10.1063 / 1.5082510$

Batubara R, Nurminah M, Hanum TI, Surjanto. 2019. Potency of gaharu leaves that grows naturally and cultivately as raw material of antioxidant-rich tea. Proceedings International Conference on Environmental Awareness for Sustainable Development in conjunction with International Conference on Challenge and Opportunities Sustainable Environmental Development, ICEASD \& ICCOSED 2019, 1-2 April 2019, Kendari, Indonesia. DOI: 10.4108/eai.1-4-2019.2287276

Batubara R, Surjanto, Hanum TI, Handika A, Afandi O. 2020. Phytochemical screening and antioxidant activity of agarwood leaves (Aquilaria malaccensis) from two sites in North Sumatra, Indonesia. Biodiversitas 21 (4): 1588-1596. DOI: 10.13057/biodiv/d210440

Chang X, Lu Y, Lin Z, Qiu J, Guo X, Pan J, Abbasi AM. 2018. Impact of leaf development stages on polyphenolics profile and antioxidant activity in Clausena lansium (Lour.) Skeels. BioMed Res Int. DOI: $10.1155 / 2018 / 7093691$
Ditjen POM. 1995. Indonesian Materia Medica. Volume IV. Ministry of Health, Jakarta. [Indonesian]

Farnsworth NR. 1996. Biological and phytochemical screening of plants. J Pharm Sci 55 (3): 263.

Gao N, A Li, C Quan, L Du, Y Duan. 2013. TG-FTIR and Py-GC/MS analysis on pyrolysis and combustion of pine sawdust. J Anal Appl Pyrolysis 100: 26-32. DOI: 10.1016/j.jaap.2012.11.009

Hasan Z, Denian AI, Tamsin AJP, Burhaman B. 2000. Budidaya dan pengolahan gambir. Institute for Agricultural Technology Studies. Palembang. [Indonesian]

Hashim YZHY, Kerr PG, Abbas P, Salleh HM. 2016. Aquilaria spp. (agarwood) as source of health beneficial compounds: A review of traditional use, phytochemistry and pharmacology. J Ethnopharmacol 189: 331-360. DOI: 10.1016/j.jep.2016.06.055

Izzreen NQ, Fadzelly M. 2013. Phytochemicals and antioxidant properties of different parts of Camellia sinensis leaves from sabah tea plantation in Sabah, Malaysia. Int Food Res J 20 (1): 307-312.

Liu Z, Bruinsc ME, de Bruijna WJC, Vinckena JP. 2020. A comparison of the phenolic composition of old and young tea leaves reveals a decrease in flavanols and phenolic acids and an increase in flavonols upon tea leaf maturation. J Food Compos Anal 86: 103385. DOI: 10.1016/j.jfca.2019.103385

Mega IM, Swastini DA. 2010. Phytochemical screening and antifree radical activity of agarwood (Gyrinops versteegii) leaf methanol extract. Jurnal Kimia 4(2): 187-192. [Indonesian]

Mulyaningsih T, Yamada. 2008. Notes on some species of agarwood in Nusa Tenggara, Celebes and West Papua. In book : Natural Resource Management and Socio-Economic Transformation under The Decentralization in Indonesia: Toward Sulawesi area studies. Publisher CSEAS, Kyoto University, Kyoto.

Molyneux P. 2004. The use of the stable free radical diphenylpicrylhydrazyl (DPPH) for estimating antioxidant activity. Songklanakarin J Sci Technol 26: 212-219.

Pambayun RM, Gardjito M, Sudarmadji S, Kepti R K. 2017. Phenolic content of Gambier (Uncaria gambir Roxb) leaves extract and its antibacterial activity. Agritech 27 (2): 89-94. [Indonesian]

Parwata A, Manuaba P, Yasa S, Bidura IGNG. 2016. Characteristics and antioxidant activities of gaharu (Gyrinops versteegii) leaves. J Biol Chem Res 33 (1): 294-301.

Prakash A. 2001. Antioxidant activity. Analytical Progress 19 (2): 1-4.

Sattayasai J, Bantadkit J, Aromdee C, Lattnann E, Airarat W. 2012. Antipyretic, analgesic and anti-oxidative activities of Aquilaria crassna leaves extract in rodents. J Ayurveda Integr Med 3 (4): 175179. DOI: 10.4103/0975-9476.104427.

Sithole B, L Lapierere, C Wanatabe. 2013. A study of polymerization of aspen (Populus) wood lipophilic extractives by SEC and Py-GC/MS. Appita J 66 (1): 59-65.

Sumarna Y. 2002. Agarwood Cultivation, Seri Agribisnis. Penebar Swadaya, Jakarta [Indonesian]

Sumarna Y. 2012. Agarwood-producing plants cultivation. Forestry Research and Development Agency, Center for Research and Development of Forest Productivity. Ministry of Forestry. Bogor. [Indonesian]

Surjanto, Batubara R, Hanum TI, Julianti E. 2019. Potency of fresh and rotten leaves of gaharu (Wikstroemia tenuiramis Miq) Sumatera endemic as raw material of antioxidant-rich tea. IOP Conf Ser Earth Environ Sci 305: 012061. DOI: 10.1088/1755-1315/305/1/012061

Tehubijuluw H, Watuguly T, Tuapattinaya PMJ. 2018. Flavonoids content analysis of tea drinks from seagrass (Enhalus acoroides) leaves based on leaves maturity. Biopendix 5 (1): 1-7. DOI: 10.30598/biopendixvol5issue1 page1-7. [Indonesian]

Tony MFI, Tualeka A, Tongo-tongo M. 2017. Identification of chemical compound of octadecadienal acid contained in methanol extract of pangi leave (Pangium edule Reinw). Int J Health Med Curr Res 2 (2): 469-473.

Ware AE. 2013. Application of Pyrolysis-GC/MS to The Study of Biomass and Biomass Constituents. [Dissertation]. University of Kentucky, USA.

Zhang L, Gao Y, Zhang Y, Liu J, Yu J. 2010. Changes in bioactive compounds and antioxidant activities in pomegranate leaves. Scientia Horticulturae 123: 543-546. DOI: 10.1016/j.scienta.2009.11.008 